\title{
CONTRIBUIÇÃO DE PIERRE BOURDIEU PARA COMPREENSÃO DA EFETIVIDADE DAS DECISÕES DA CORTE INTERAMERICANA DE DIREITOS HUMANOS
}

\section{Ana Carolina Lopes Olsen ${ }^{1}$}

\begin{abstract}
Resumo
O sistema interamericano de direitos humanos respondeu a uma insuficiência do direito interno dos Estados latino-americanos em promover e proteger direitos de seus cidadãos. Todavia, as decisões proferidas por seu órgão jurisdicional, a Corte Interamericana, enfrenta graves resistências dos Estados-membros para serem implementadas, notadamente quando determinam responsabilização e punição dos agentes responsáveis pela violação de direitos humanos. A partir das categorias de Pierre Bourdieu, como o campo jurídico e o poder simbólico, procurou-se demonstrar a configuração de um campo social inerente à atuação dos órgãos desse sistema, a fim de investigar a baixa efetividade dessas decisões.
\end{abstract}

Palavras-chave: Corte Interamericana. Sentença. Campo. Violência simbólica.

\section{INTRODUÇÃO}

A criação de um sistema interamericano destinado à promoção e à proteção dos direitos humanos representa um avanço em relação à valorização ética do ser humano, bem como à limitação do poder soberano dos Estados no tocante à preservação da dignidade humana. Se a América Latina foi palco de severas ditaduras militares no século XX, procura, no século XXI, reconhecer a necessidade de organismos internacionais capacitados para implementar normas internacionais as quais estes Estados livremente aderem. Todavia, se de um lado é inegável o avanço no plano da estruturação de um sistema de proteção, por outro a dificuldade na implementação de suas decisões corresponde a um desafio ainda a ser enfrentado. A Corte Interamericana, na qualidade de autêntico órgão jurisdicional, emite sentenças definitivas que exigem dos Estados obrigações de indenizar vítimas, mas, sobretudo, de prevenir novas violações de direitos humanos e punição dos responsáveis por essas violações. Dificilmente as obrigações de fazer ou não fazer são efetivamente cumpridas pelos Estados.

Trata-se de questão que não pode ser resolvida exclusivamente através da ciência do direito, mas exige

\footnotetext{
${ }^{1}$ Doutoranda em Direito na PUC-PR, área de concentração Direito Socioambiental e Sustentabilidade, linha de pesquisa Justiça, Democracia e Direitos Humanos. E-mail: anac.olsen@gmail.com
} 
outros olhares e partir de um método científico ${ }^{2}$ capaz de promover uma investigação do objeto de forma coerente, racional e produtiva.

É dentro desse ambiente que o método elaborado por Pierre Bourdieu pode auxiliar na compreensão da baixa efetividade dessas decisões internacionais, bem como na identificação de alternativas. Trata-se de uma tentativa de compreender o problema indo além das pautas normativas, a fim de "ampliar os processos compreensivos acerca do humano, de sua natureza, da sua cultura como uma dimensão de sua natureza, de suas normas como uma das dimensões de sua forma, de seu viver" (WEIL, 2010, p. 86). Ainda que o sociólogo não tenha se debruçado especificamente sobre o Direito como objeto principal de análise, elaborou categorias que permitem compreender seu funcionamento, a partir de uma estrutura muito específica, agentes dotados de linguagem e comportamento que personificam e preservam essa estrutura. A noção de campo social, bem como de violência simbólica assumem uma importância especial nesse estudo.

Assim, o presente artigo se divide em três partes. Na primeira, buscou-se resgatar as razões que justificam a existência de um sistema regional de proteção dos direitos humanos, a partir de experiências históricas comuns aos povos da América Latina, que justificaram a criação da Convenção Americana dos Direitos Humanos, bem como dos órgãos que promovem sua aplicação aos casos concretos, como a Comissão Interamericana de Direitos Humanos e a Corte. Esta última, na qualidade de órgão jurisdicional, é a figura que permite a compreensão desse sistema a partir das categorias bourdieusianas, como o campo, o habitus e a violência simbólica. Este enquadramento e a afirmação de um campo do sistema interamericano de direitos humanos são objeto da segunda parte do artigo. Na terceira parte, pretende-se compreender especificamente a baixa efetividade das decisões judiciais proferidas pela Corte Interamericana, à luz das contribuições de Bourdieu.

A questão da efetividade das decisões internacionais frente a estrutura soberana dos Estados está longe de ser esgotada no presente estudo. Procura-se apenas buscar ferramentas fora da ciência jurídica para permitir uma visão diferenciada da questão, e quem sabe apontar caminhos.

\section{SISTEMA JURÍDICO REGIONAL DE PROTEÇÃO DOS DIREITOS HUMANOS}

O século XX foi profundamente marcado pelos conflitos armados, que colocaram as populações dos países em estado de miséria humana. Foi o século em que o homem enfrentou seu maior desafio enquanto espécie: o risco concreto de aniquilação. A ameaça nuclear evidenciou a vulnerabilidade humana a ponto de colocar em pauta a urgência de se criar mecanismos para mudar o curso histórico, propiciando uma mirada para o

\footnotetext{
${ }^{2}$ Método é nesse trabalho compreendido como "um referencial ou quadro teórico conceitual de linha filosófica, religiosa, política, ideológica, sobre um autor, pesquisador e/ou estudioso, ou categoria que sirva para diferenciar ou comparar o modo de compreensão do sujeito sobre o objeto de estudo" (TAVARES NETO; MEZZAROBA, 2016, p. 1).
} 
abismo, e a tentativa de se empreitar uma caminhada em sentido contrário. (BOBBIO, 2009, p. 253) $)^{3}$

Também o direito, concebido como um sistema jurídico instituído por um Estado nacional, mostrou mais que a impotência diante da miséria humana. Mostrou ser ele o responsável por desencadear e perpetuar essa miséria, como se verificou através do processo instituído enquanto política pública para aniquilação de seres humanos no III Reich Nazista. Os campos de concentração corresponderam a um projeto político de extermínio de pessoas a quem fora negada sua própria humanidade (PIOVESAN, 2015, p. 45).

Como bem assinala Cançado Trindade (2003, p. 50):

No hay que olvidarse que el positivismo jurídico dotó el Estado de "voluntad propia" y redujo los derechos de los seres humanos a los que el Estado a éstos "concedía"; en el plano normativo, el positivismo se mostró subserviente al orden legal establecido, y convalidó los sucesivos abusos practicados, em nombre de éste, contra el ser humano.

Diante desse quadro, a humanidade reconheceu que nenhum outro passo poderia ser tomado naquela direção; estava-se em processo de destruição da própria espécie. O direito não poderia ser um sistema que gerava não só violência, mas promovia o não reconhecimento do outro, sua estigmatização em uma categoria de indesejáveis (ARENDT, 2012, p. 300; 331).

A partir da instituição do Tribunal de Nuremberg, ficou patente a necessidade de se estabelecer uma responsabilidade pela preservação do homem, e pelo reconhecimento de toda pessoa como sujeito de direitos, para além dos limites do direito nacional interno. A soberania estatal não mais poderia ser o escudo protetor de qualquer prática jurídica, de qualquer direito. Era necessário resgatar o homem enquanto valor ético fundamental e estabelecer mecanismos a partir dos quais os Estados se comprometeriam em reconhecer direitos humanos e implementá-los (PIOVESAN, 2015, p. 45-47; 81).

Nesse contexto, a Carta de São Francisco de 1945 instituiu a Organização das Nações Unidas que tinha, dentre seus objetivos, precisamente comprometer os Estados a reconhecer e fazer cumprir os direitos humanos. Em 1948 foi assinada a Declaração Universal dos Direitos Humanos, instituindo um mínimo ético universal atribuível a toda pessoa, independentemente de sua vinculação jurídica a um Estado Nacional (COMPARATO, 2015, 68-69). Fundava-se assim a fase contemporânea dos direitos humanos, marcada pela existência de instituições internacionais responsáveis pela criação e aplicação de documentos jurídicos internacionais, vinculantes para os Estados; e pela relativização da soberania, a qual não mais poderia ser invocada para legitimar ordenamentos jurídicos e instituições estatais destinadas à violação dos direitos humanos (PIOVESAN, 2015, p. 47).

\footnotetext{
${ }^{3}$ Essa caminhada não pode implicar a instituição de novas e mais potentes armas, como se viu no período da Guerra Fria, bem salientado e condenado por Norberto Bobbio: "A novidade paradoxal, perturbadora, e, acrescento eu, indecente, dessa fórmula está na inversão de uma verdade que pareceu óbvia ao longo de todo o curso da história humana. Os homens sempre acreditaram que o único modo de abolir as guerras fosse jogar fora as armas. Os fautores do equilíbrio do terror, ao contrário, querem nos fazer
} vol.10, nº. 03, Rio de Janeiro, 2017.pp. 1432-1452 
Paralelamente ao sistema internacional de proteção dos direitos humanos, surgiu nas Américas o sistema regional instituído a partir da Organização dos Estados Americanos. Aqui, a primeira preocupação a respeito da instituição de um sistema internacional não foi a salvaguarda de direitos humanos, mas a sobrevivência econômica dos países envolvidos. Os Estados americanos estavam bastante preocupados com o seu próprio desenvolvimento, e esperavam dos Estados Unidos - elevados à superpotência na repartição bipolar do mundo após o final da II Guerra - uma ajuda financeira parecida com a do Plano Marshall. Reuniram-se em Bogotá em 1948 para a criação da Organização dos Estados Americanos, e estabeleceram uma declaração de direitos muito similar à aprovada no plano internacional (CORREIA, 2008, p.92).

Num primeiro momento, esse sistema regional estava dividido entre Estados Unidos de um lado, em avançado processo de industrialização que viam na América Latina um mercado a ser explorado, e países latinoamericanos, que buscavam encontrar na OEA garantias políticas para sua autonomia e independência. Assim a Carta da OEA determinava a solução pacífica das controvérsias, a consolidação da democracia e um regime de cooperação entre os Estados americanos (CORREIA, 2009, p.93).

A preocupação com os direitos humanos só ganhou corpo com a criação da Convenção Americana de Direitos Humanos, aprovada na Conferência de São José da Costa Rica em 1969, em vigor a partir de 1978, reproduzindo basicamente direitos humanos previstos no Pacto Internacional de Direitos Civis e Políticos de 1966 ${ }^{4}$. Logrou aferir substancial adesão dos países que integram o bloco regional ${ }^{5}$, que, ao aderirem ao instrumento normativo aceitavam a flexibilização de sua soberania no sentido de reconhecer um sistema jurídico supranacional como estrutura legítima de imposição de condutas. O próprio texto da Convenção exige que os Estados adotem as medidas legislativas, administrativas ou outras necessárias à proteção e promoção dos direitos humanos nela enunciados, o que demonstra sua inequívoca pretensão de garantir a maior efetividade possível a esses direitos, determinado aos Estados um autêntico comprometimento.

Esta estrutura jurídica regional, com existência paralela e autônoma em relação ao sistema internacional, acabou encontrando uma justificativa própria para sua consolidação, em virtude das particularidades vividas pelos países americanos (PIOVESAN, 2015, p. 100-101). Ainda que o terror do nazismo e da ameaça nuclear não tenham se sentido de forma tão premente em solo americano, também esses países conviveram com regimes

acreditar que, para eliminar a guerra, não podemos destruir as armas, devemos sim torna-las cada vez mais potentes e mortíferas, de modo a dissuadir os dois máximos contentores de utilizá-las" (2009, p.253).

${ }^{4}$ Como salienta Comparato, a Organização dos Estados Americanos deixou para regular posteriormente direitos sociais, econômicos e culturais, o que vez na Conferência Interamericana de San Salvador, de 1988, em que diversos países aderiram ao Protocolo Adicional. O Brasil aderiu tanto à Convenção Americana, em 1992 (Decreto n. 4463) quanto ao Protocolo Adicional, em 1995 (Decreto-Legislativo n. 56). (2015, p. 380-381).

${ }^{5}$ Dos 35 países que compõem a OEA, assinaram 25: Argentina, Barbados, Bolívia, Brasil, Chile, Colômbia, Costa Rica, Dominica, Equador, El Salvador, Granada, Guatemala, Haiti, Honduras, Jamaica, Mexico, Nicarágua, Panamá, Paraguai, Peru, República Dominicana, Suriname, Trinidad e Tobago, Uruguai e Venezuela. (CORREIA, 2009, p. 100). Evidencia-se que Estados Unidos distanciaram-se do sistema regional, na medida em que não ratificaram a Convenção. 
autoritários, que deixaram um legado de violação de direitos humanos. Os países americanos convivem com problemas que the são bastante peculiares, como a desigualdade e a exclusão social, os altos índices de violência e de impunidade, bem como a precariedade do rule of law e da frágil tradição de respeito aos direitos humanos (PIOVESAN, 2015, p. 137).

Apesar de terem passado por um intenso processo de democratização nas décadas de 80 e 90, os países latino-americanos ainda convivem com as heranças deixadas pelas rupturas com o Estado de Direito. Como coloca Paulo Weil (2010, p.87), a América Latina convive com o paradoxo decorrente do reconhecimento formal dos direitos humanos em suas cartas constitucionais (tanto civis e políticos, quanto sociais, econômicos e culturais), mas com uma realidade de pobreza e desigualdade, em decorrência da adoção de modelos liberais de Estado que acabaram por desaparelhá-lo como instrumento de concretização desses direitos. Uma combinação como esta levou ao aumento e à diversificação da violência, como demonstram os conflitos agrários e a persistência do trabalho em condições análogas a de estravo (WEIL, 2010, p. 87).

Importante verificar que a Convenção Americana de Direitos Humanos foi firmada em 1969, mas desde 1964 o Brasil já enfrentava uma Ditadura Militar ${ }^{6}$ e desde 1968, com a edição do Ato Institucional n. 57 havia suspenso garantias constitucionais muito caras à preservação e proteção da dignidade humana, como o habeas corpus. A implementação de ditaduras militares alinhadas com a direita foi uma constante latino-americana ${ }^{8}$, desencadeando ondas de perseguição, desaparecimento forçado, torturas, censura, e cassação de direitos políticos.

Diante desses problemas o sistema regional montou uma complexa estrutura jurídica, ancorada na tríade formada pela Convenção Americana, enquanto documento normativo; pela Comissão Interamericana, órgão especialmente responsável pela proteção dos direitos humanos em sentido amplo, e a Corte Interamericana,

\footnotetext{
${ }^{6}$ Precisamente por isso só aderiu à Convenção em 1992, depois da democratização assegurada pela Constituição Federal de 1988. ${ }^{7} \mathrm{O}$ Ato Institucional n. 5, de 13/12/1068 suspendia diversos direitos humanos essenciais à democracia e à dignidade humana: Art. $2^{\circ}$ - O Presidente da República poderá decretar o recesso do Congresso Nacional, das Assembléias Legislativas e das Câmaras de Vereadores, por Ato Complementar, em estado de sitio ou fora dele, só voltando os mesmos a funcionar quando convocados pelo Presidente da República; Art. $4^{\circ}$ - No interesse de preservar a Revolução, o Presidente da República, ouvido o Conselho de Segurança Nacional, e sem as limitações previstas na Constituição, poderá suspender os direitos políticos de quaisquer cidadãos pelo prazo de 10 anos e cassar mandatos eletivos federais, estaduais e municipais; Art. 10 - Fica suspensa a garantia de habeas corpus, nos casos de crimes políticos, contra a segurança nacional, a ordem econômica e social e a economia popular; Art. 11 Excluem-se de qualquer apreciação judicial todos os atos praticados de acordo com este Ato institucional e seus Atos Complementares, bem como os respectivos efeitos (BRASIL, 1968).

${ }^{8}$ Em breve síntese: (i) golpe de Estado na Guatemala, em 1954; (ii) no Paraguai o general Alfredo Stroessner comandou um golpe contra o presidente Federico Chávez e assumiu o poder, nele permanecendo por 35 anos; (iii) na Argentina, em 1962, militares tomaram o poder derrubando o presidente Arturo Frondizi, em 1976, outro golpe afastou do poder a Presidente Isabelita Perón; (iv) a Bolívia sofreu um golpe de Estado em 1964, com a deposição do presidente esquerdista Victor Paz Estenssoro, e ingressou em um período de grave instabilidade política, sendo que a democracia só retornou em 1985 com a eleição do mesmo Estenssoro; (v) também em 1965 a República Dominicana mergulhou em ditadura militar com o golpe contra o presidente eleito Juan Emilio Bosch Gaviño; (vi) em 1968, o Peru sofreu golpe de Estado e assumiu o poder general Juan Velasco Alvarado; (vii) Em 1973 a ditadura militar chega ao Chile, com a deposição do presidente Salvador Allende e a tomada do poder pelo general Augusto Pinochet; (viii) no Uruguai, a ditadura militar teve início em 1973, em que o presidente eleito Juan María Bordaberry suspendeu a constituição, fechou o congresso e passou a governar como ditador. (BECATTINI, 2013)
} 
órgão jurisdicional responsável pelo julgamento dos casos de violação de direitos humanos.

Ainda que haja posições defendendo a baixa juridicidade desse sistema (NIETO NAVIA, 1988), é preciso reconhecer a preocupação do sistema interamericano de promover, entre os países do bloco regional, a adoção de mecanismos eficazes, como a petição individual através da qual um indivíduo, alçado à estatura de sujeito de direitos no plano internacional, pode denunciar a violação de direitos humanos por parte de um Estadomembro (CANÇADO TRINDADE, 2003, p.59-60; 70).

É nesse sentido que o sistema aparelhou a Comissão Interamericana de Direitos Humanos, e um órgão jurisdicional com poder para interpretar e aplicar a Convenção, inclusive determinando condutas aos Estados que violem esses direitos: a Corte. Trata-se, como coloca Piovesan, de aliar "a gramática de direitos e a gramática de deveres; ou seja, os direitos internacionais impõem deveres jurídicos aos Estados (prestações positivas e/ou negativas), no sentido de respeitar, proteger e implementar os direitos humanos" (2015, p. 106).

A Comissão Interamericana já havia sido criada antes da Convenção Americana dos Direitos Humanos, em função de sua previsão na própria Carta da OEA, artigo 106. Criada em 1958, por ocasião da $5^{\text {a }}$ Reunião de Consulta dos Ministros das Relações Exteriores, teve seus poderes significativamente ampliados com a Convenção, que previu competência para receber denúncias individuais ou feitas por outros Estados a respeito de violação de direitos humanos, sua diligência no recebimento dos relatórios estatais bem como na determinação da adoção de medidas de urgência necessárias à proteção de direitos humanos pelos Estados. Trata-se de órgão formado por sete membros, cada um de um Estado pertencente a OEA, de notório conhecimento sobre direitos humanos, que atuam de forma autônoma em relação aos Estados dos quais são cidadãos. (CORREIA, 2009, p. 108)

A Corte é verdadeiro órgão jurisdicional, também formada por sete membros de Estados da OEA, eleitos pela Assembleia Geral para um mandato de seis anos, sendo possível uma única reeleição. Ela desempenha uma função consultiva de interpretação da Convenção Americana e tratados internacionais dos quais os Estados americanos sejam parte, mediante a emissão de pareceres (art. 64); e uma função contenciosa, em que Comissão Interamericana de Direitos Humanos e Estados-membros podem denunciar casos de violação de direitos humanos previstos na Convenção por parte de outros Estados-membros da OEA. Neste último caso, desenrolase autêntico processo judicial que poderá culminar em uma solução amistosa, em que o Estado reconhece a violação e acorda a adoção de condutas para reparar os danos dela decorrentes, bem como prevenir novas violações (art. 53, Regulamento Interno da Corte), ou em sentença judicial (arts. 63 e 68 da Convenção Americana de Direitos Humanos).

Um dos aspectos determinantes da eficácia da atuação jurisdicional da Corte é o fato de que ela só decide casos que forem apresentados contra Estados que tenham, expressamente, reconhecido sua competência 
(art. 62 da Convenção Americana de Direitos Humanos). O Brasil reconheceu essa competência em 1998, colocando-se ao lado da maioria dos Estados-membros da $\mathrm{OEA}^{9}$, mas é preciso ressaltar que a maior potência econômica e política do continente, os Estados Unidos, tendo assinado a Convenção Americana de Direitos Humanos em 1977, jamais a ratificou, e, portanto, não reconhece a competência da Corte. Significa dizer que o sistema regional de proteção dos direitos humanos acaba tocando apenas os países latino-americanos, o que implica uma identidade bastante específica. Tem-se enfatizado que um dos primeiros desafios para a implementação das decisões da Corte é precisamente lograr auferir o reconhecimento de todos os países que aderiram à Convenção Americana de Direitos Humanos (CANÇADO TRINDADE, 2003, p. 31).

Ainda assim, mesmo contando com uma significativa adesão dos Estados-membros da OEA, é da própria lógica do sistema um menor poder de implementação das decisões proferidas em sede internacional. Duarte Junior reconhece a existência de um embate entre o direito interno dos Estados e o direito internacional, na medida em que ambos têm um poder de coerção profundamente diferenciado. Enquanto o direito interno goza de uma ampla estrutura de coerção (hard law), o direito internacional (soft law), por precisar se adequar a uma concepção ainda resistente em diversas searas de soberania, e submete-se a um sistema global de poderes assimétricos, carece da mesma exequibilidade (DUARTE JUNIOR, 2008, p. 21).

É nesse sentido que as teorizações de Pierre Bourdieu, grande sociólogo contemporâneo, podem fornecer um instrumental capaz de permitir a compreensão dessa dificuldade.

\section{O CAMPO DO SISTEMA REGIONAL DOS DIREITOS HUMANOS}

Embora não tenha tido por foco central de suas preocupações o sistema jurídico, Pierre Bourdieu dedicou-se ao seu estudo em "O poder simbólico", como pertencente a um campo social dotado de especificidades em relação às pressões externas, "no interior do qual se produz e se exerce a autoridade jurídica, forma por excelência da violência simbólica legítima cujo monopólio pertence ao Estado e que se pode combinar com o exercício da força física" (2002, p. 211). A lógica desse campo jurídico estaria, de um lado, nas relações de força específicas que determinam sua estrutura e as lutas de concorrência, e, de outro lado, na lógica interna das obras jurídicas que delimitam o universo das soluções propriamente jurídicas (BOURDIEU, p. 211).

Verifica-se que para Bourdieu, a realidade social deveria ser compreendida a partir do método construtivista estruturalista:

Por estruturalismo, ou estruturalista, quero dizer que existem, no próprio mundo social e não

\footnotetext{
${ }^{9}$ Os 25 Estados que reconheceram a obrigatoriedade da competência da Corte Interamericana são: Argentina, Barbados, Bolívia, Brasil, Colômbia, Costa Rica, Chile, Dominica, Equador, El Salvador, Granada, Guatemala, Haiti, Honduras, Jamaica, México, Nicarágua, Panamá, Paraguai, Peru, República Dominicana, Suriname, Trinidad e Tobago, Uruguai e Venezuela (CORTE INTERAMERICANA DE DIREITOS HUMANOS)
} 
apenas nos sistemas simbólicos - linguagem, mito, etc. -, estruturas objetivas, independentes da consciência e da vontade dos agentes, as quais são capazes de orientar ou coagir suas práticas e representações. Por construtivismo, quero dizer que há, de um lado, uma gênese social dos esquemas de percepção, pensamento e ação que são constitutivos daquilo que chamo de habitus e, de outro, das estruturas sociais, em particular do que chamo de campos e grupos, e particularmente do que se costuma chamar de classes sociais (BOURDIEU apud PETERS, 2013).

Há um movimento dialético circular entre comportamento e estrutura (que seria historicamente reversível) mas que gera uma tendência à reprodução de práticas sociais e relações de poder. Essa dialética permite compreender como que a forma de pensar e agir do sujeito é determinada pela estrutura, e, ao passo em que se realiza, acaba por contribuir para a manutenção e preservação dessa mesma estrutura (PETERS, 2013, p. 60).

Para se compreender o Direito segundo o método criado por Bourdieu, há que se atentar para as estruturas sociais como determinantes das condutas das pessoas, como as normas jurídicas, os tribunais, os departamentos estatais encarregados de operacionalizar os processos judiciais e mesmo os mecanismos de repressão jurídica, como a polícia judiciária. Os atores desse campo, que trazem consigo toda a sua bagagem de comportamentos e história, todavia, também influenciam as estruturas, podendo modifica-las para atender seus objetivos nas trocas de poder simbólico (PETERS, 2013, p. 60).

Embora tenha pensado o campo jurídico para a figura do direito interno, pretende-se demonstrar que é possível também compreender a estrutura do sistema jurídico interamericano, juntamente como seus atores, segundo a forma de compreensão do mundo inaugurada por Bourdieu, especialmente a partir da categoria do campo, da violência simbólica e dos processos de dominação que lhe são inerentes.

Para Bourdieu, o campo corresponde a "um estado da relação de força entre os agentes ou as instituições envolvidas na luta ou, se se preferir, da distribuição do capital específico que, acumulado no decorrer das lutas anteriores, orienta as estratégias posteriores" (BOURDIEU, 2003, p. 120). Neste espaço materializam-se os habitus como "mediação entre as condições sociais existentes e as ações individuais (...), historicamente construídas, auxiliando no entendimento de uma homogeneidade de grupos que tenham uma trajetória social em comum" (SANTOS, p. 88). O campo acaba por funcionar como um espaço social em que há um jogo especializado, cujos atores disputam o monopólio da violência legítima a partir de seu capital, o qual, por sua vez, corresponde ao conjunto de recursos que são reconhecidos como valiosos pelos membros do campo e pelas regras desse jogo (não sendo necessariamente econômico). Existe, assim, uma tensão constante entre dominantes e dominados no campo, os primeiros preocupados em preservar o capital social conquistado, e os últimos focados na exposição da ilegitimidade desse capital social. Trata-se de um movimento que acaba por reforçar a estrutura de dominação, na medida em que as próprias lógicas das regras de funcionamento do campo não são questionadas (SANTOS, p. 90-91).

Como Bourdieu bem enfatizou, trata-se de um conceito aberto e, portanto aplicável a várias realidades. 
Os conceitos não podem ser hermeticamente fechados, sob risco de perderem sua operacionalidade, mas devem justamente permitir a compreensão de situações concretas, e podem inclusive evoluir (BOURDIEU, 2003, p. 127). Cada campo tem especificidades próprias, as quais, na medida em que são estudadas ${ }^{10}$, permitem que se extraia as validades universais que estão presentes em todos os campos, mas que assumem feições diferenciadas a partir das características secundárias (BOURDIEU, 2003, p. 119). O que há de comum em todos os campos, segundo Bourdieu, é a luta inerente aos processos de dominação, são regras universais a todos os campos que permitem que se promova a sua identificação como tal. Trata-se do conceito de homologia, tal como explicado por Tavares Neto e Mezzaroba (2016, p. 12-13):

Homologia na linguagem bourdieusiana se refere aos processos de estruturação objetiva comuns aos mais diversos campos sociais, ou seja, a possibilidade de observação pela equiparação entre suas formas de funcionamento sem a destruição de suas relativas autonomias no interior do campo social, tais como o campo do direito, do jornalismo, da Ciência Política, da biologia, matemática.

O campo jurídico foi concebido por Bourdieu tendo por referência o direito interno, produzido por um Estado e por seus órgãos implementado. Nesse campo, existe um processo de violência simbólica que os dominantes - os juízes - realizam em relação aos demais (advogados, funcionários do Poder Judiciário, justiciáveis), no momento em que promovem a interpretação do direito com autoridade, a qual é reconhecida como legítima na medida em que atende a certos pressupostos, como legalidade, constitucionalidade, fundamentação racional. É nesse campo jurídico, portanto, que se realiza o monopólio dos agentes técnicos e sociais com autoridade para dizer o direito, definindo, portanto qual é a forma "legítima e justa" do mundo social (BOURDIEU, 2002, p. 212).

Assim como no campo jurídico tradicional, no campo do sistema interamericano dos direitos humanos também há uma divisão do trabalho entre magistrados e doutrinadores, sendo que cabe aos primeiros, mais propriamente aos sete juízes da Corte Interamericana, definir a interpretação e a aplicação da Convenção Americana de Direitos Humanos.

Na visão de Bourdieu, no campo do direito há uma disputa pela autoridade e pelo poder entre dois grandes grupos, professores que interpretam o direito para o campo puramente teórico da doutrina (teóricos); e magistrados que interpretam o direito para a aplicação prática, aos casos concretos (práticos). O sentido do direito é dado justamente pela confrontação entre esses diversos intérpretes, que representam interesses específicos a respeito da aplicação/interpretação da lei (BOURDIEU, 2002, p. 233).

A própria forma do campo jurídico depende da força relativa dos teóricos e dos práticos em um dado

\footnotetext{
${ }^{10}$ Para Montagner, o conceito de campo, como categoria geral, pode engendrar o reconhecimento de diversos campos específicos, com ora se pretende: "Sua utilização permite, como se fora uma profecia auto-realizável, ao mesmo tempo uma análise de um determinado espaço social específico e, nos casos nos quais ainda não existia um determinado campo, a sua própria inauguração fundadora (considerando que os intelectuais são os operadores da criação simbólica)”. (2010, p. 256)
} 
momento histórico, e de sua capacidade de impor sua interpretação do direito. Mas entre esses dois atores, há um antagonismo meramente aparente, pois sua atuação é, em verdade, complementar. As funções se integram dentro da divisão do trabalho de dominação simbólica, na qual os adversários, objetivamente cúmplices, se servem uns aos outros. Juízes se servem das interpretações doutrinárias em suas sentenças, e passam a dotá-las de autoridade simbólica. Teóricos estudam a produção judicial e sobre ela produzem novas teorias, delineando em um processo dialético o sentido da implementação do direito aos casos concretos. E o juiz encontra legitimação para sua prática precisamente na interpretação feita pelos doutrinadores, através de uma cadeia de legitimidade, de modo que seus atos escapam da violência arbitrária (BOURDIEU, 2002, p. 226).

Importante que se diga que assim como no campo do direito interno, no campo do sistema interamericano de direitos humanos muitos teóricos já com grande capital jurídico (ou seja, amplamente reconhecidos pela validade de suas teorizações) conseguem alçar a carreira de juízes da Corte Interamericana, escolhidos pela Assembleia Geral da OEA. A concepção protetora de direitos humanos defendida na academia do Direito passa a integrar decisões judiciais e se eleva em violência simbólica garantindo, em tese, grande eficácia na proteção desses direitos.

No caso do sistema interamericano, essa influência é bastante evidente. Da composição atual da Corte ${ }^{11}$, os juízes Eduardo Ferrer Mac-Gregor Poisot ${ }^{12}$, Eduardo Renato Vio Grossi ${ }^{13}$, Elizabeth Odio Benito ${ }^{14}$, Eugenio Raúl Zaffaroni ${ }^{15}$ e L. Patricio Pazmiño Freire ${ }^{16}$ são egressos ou mantém carreira acadêmica. Assim, se teóricos defendem uma concepção contemporânea de direitos humanos que alça o indivíduo à categoria ética fundamente das normas jurídicas, esta concepção permeia também as decisões e as recomendações oriundas da Corte. Verifica-se, assim, uma "coesão social do corpo dos intérpretes" nesse campo em históricas da razão jurídica

\footnotetext{
${ }^{11}$ Composição atual da Corte Interamericana de Direitos Humanos: Roberto de Figueiredo Caldas (Brasil - Presidente até 2018); Eduardo Ferrer Mac-Gregor Poisot (México); Eduardo Vio Grossi (Chile); Elizabeth Odio Benito (Costa Rica); Eugenio Raúl Zaffaroni (Argentina); Humberto Antônio Sierra Porto (Colômbia) e L. Patrício Pazmiño Freire (Equador). CORTE INTERAMERICANA DE DERECHOS HUMANOS. Composición Actual. San Jose, 2016. Disponível em: <www.corteidh.or.cr/index.php/es/acerca-de/composicion>. Acesso em 10 ago. 2016.

${ }^{12}$ Investigador titular por oposición em el Instituto de Investigaciones Jurídicas de la Universidad Nacional Autónoma de México (UNAM) e investigador nível III del Sistema Nacional de Investigaciones del Consejo Nacional de Ciencia y Tecnologia. Professor Titular por oposición de la asignatura Derecho procesal constitucional em la Faculdad de Derecho de la Universidad Nacional Autónoma de México (UNAM). Disponível em <https://es.m.wikipedia.org/wiki/Eduardo_Ferrer_MacGregor_Poisot $\geq$. Acesso em 10 ago. 2016.

13 Doctor en Derecho Público de la Universidad Pierre Mendès France, Grenoble 2, 1976. Disponível em $<$ www.corteidh.or.cr/sitios/compos 14/EVG.html $\geq$. Acesso em 10 ago. 2016

${ }^{14}$ Professora Catedrática de la Universidad de Costa Rica, Facultad de Derecho en 1986, e Professora Emérita en 1995. Disponível em: <http://www.corteidh.or.cr/tablas/EOB.pdf>. Acesso em 10 ago. 2016.

15 Profesor Titular regular de Derecho Penal en la Facultad de Derecho y Ciencias Sociales de la Buenos Aires desde 1986 hasta 2007, Director del Departamento de Derecho Penal y de la Facultad de Derecho de la Universidad de Buenos Aires de 1994 hasta 2011 . Disponível em: $<$ http://www.corteidh.or.cr/tablas/ERZ.pdf>. Acesso em 10 ago. 2016

Universidad de Criminología
} vol.10, no. 03, Rio de Janeiro, 2017.pp. 1432-1452 
e à crença na visão ordenada da ordem social por eles produzida" (BOURDIEU, 2002, p.214). É o trabalho produzido pelos teóricos dos direitos humanos, complementado por aquele produzido pela Corte (ela própria também formada em grande parte por pessoas com afinidades acadêmicas) que delimita as características do campo do sistema interamericano de direitos humanos. Trata-se de um trabalho de racionalização das normas que acaba por conferir eficácia simbólica ao Direito:

O trabalho de racionalização, ao fazer acender ao estatuto de veredicto uma decisão judicial que deve, sem dúvida, mais às atitudes éticas dos agentes do que às normas puras do direito, confere-lhe a eficácia simbólica exercida por toda a acção quando, ignorada no que têm de arbitrário, é reconhecida como legítima (BOURDIEU, 2002, p. 225).

É nesse sentido que se verifica o exercício da violência simbólica no campo do sistema interamericano. Também nele é possível identificar essa "lei universal" inerente a todos os campos, segundo Bourdieu, na medida em que os atores que participam desse campo (Estados-membros da OEA, Comissão Interamericana, vítimas de violação de direitos humanos) atribuem à Corte a legitimidade para a solução dos litígios e para a interpretação autorizada da Convenção Americana de Direitos Humanos. Assim, a Corte exerce uma violência simbólica em relação aos demais membros na medida em que sentencia os casos que lhe são submetidos, e também quando emite pareceres quando provocada em sua função consultiva. Bourdieu define a violência simbólica como sendo:

(...) violência simbólica, insensível, invisível a suas próprias vítimas, que se exerce essencialmente pelas vias puramente simbólicas da comunicação e do conhecimento, ou, mas precisamente, do desconhecimento, do reconhecimento ou, em última instância, do sentimento (BOURDIEU, 1999, p. 8-9)

Interessante observar que na medida em que os dominados (aqueles que se submetem às decisões judiciais) tentam apontar impropriedades na atuação dos magistrados através de argumentos de defesa, acabam por reforçar a estrutura de dominação do próprio campo. Todavia, é preciso levar em consideração que as decisões proferidas no plano regional enfrentam dificuldades para se efetivar no plano interno do direito de cada Estado, como será abordado no próximo item, o que denota um questionamento - ainda que não declarado - das próprias regras do jogo do campo. Na medida em que os Estados invocam a soberania interna para negligenciar orientações da Comissão Interamericana, e descumprir decisões da Corte, atentam contra a própria estrutura do campo, o que lhe tira força e autonomia.

É que, na verdade, a própria estrutura internacional tem representado uma mudança para a estrutura do campo jurídico interno, pois insere ingredientes na sua lógica interna na medida em que determina que o Poder Judiciário do Estado não é mais aquele com a última palavra a determinar comportamentos para proteger os direitos humanos. A partir das teorizações de Bourdieu, pode-se reconhecer a existência de uma crise latente na estrutura do campo jurídico interno, que tem seus pressupostos questionados pela sobreposição de um

\footnotetext{
${ }^{16}$ Maestría en Derecho. Derechos económicos y sociales y culturales, 2004-2005. Universidad Andina Simón Bolívar, Ecuador. Maestría en Derecho. Derechos económicos y sociales y culturales, 2005-2006. Universidad Andina Simón Bolívar, Ecuador. Disponível em <http://www.corteidh.or.cr/tablas/LPPF.pdf>. Acesso em 10 ago. 2016.
} 
ordenamento jurídico internacional com pretensa eficácia no plano interno. ${ }^{17}$

No campo do sistema interamericano, quem se submete a esse poder simbólico mais diretamente é o justiciável, a figura da parte que leva ao Judiciário o seu caso concreto, esperando que ele determine a aplicação do Direito. Trata-se do "cliente", segundo Bourdieu, a figura do cidadão que procura entrar no campo jurídico para receber a prestação jurisdicional ainda que não domine suas regras, não fale sua língua (2002, p. 225). Como salienta Bourdieu: "Entrar no jogo, conformar-se com o direito para resolver o conflito, é aceitar tacitamente a adopção de um modo de expressão e de discussão que implica a renúncia à violência física e às formas elementares da violência simbólica, como a injúria” (2002, p. 229).

No caso do campo do sistema interamericano, essa noção tem um significado especial: levar uma violação de direitos humanos ao plano regional evidencia que o direito interno não foi capaz de proteger a integridade dos direitos da pessoa humana, significa que o Estado, no lugar de ser o agente realizador dos direitos, foi aquele que violou, ou permitiu que fossem violados, direitos essenciais à dignidade humana. Para o Estadomembro da OEA, ingressar nesse campo significa abdicar de parcela significativa de sua soberania e reconhecer a possibilidade de o órgão internacional averiguar condutas praticadas pelo Estado que sejam ilícitas, seja por violação direta de direitos humanos, seja pela própria falha no seu campo jurídico interno, incapaz de coibir essa violação, e proteger os direitos.

Austin, citado por Bourdieu, enumera três exigências para se adentrar o campo jurídico: (a) aceitar que o conflito deve ser resolvido por uma decisão entre culpado ou inocente, favorável a um ou ao outro; (b) tanto a acusação quanto a defesa devem se enquadrar nos ritos definidos pelas normas jurídicas, que estereotipam descaracterizando as nuances da vida real, o que torna os argumentos excessivamente triviais e portanto aquém das leis, ou excessivamente morais, e portanto fora da lei; (c) a aceitação dos precedentes judiciais para o enquadramento do caso, o que permite que as expressões cotidianas sejam substituídas pelas essencialmente jurídicas, que as dirtorcem. (BOURDIEU, 2002, p. 230).

No caso do campo do sistema interamericano de direitos humanos, existem diferentes classes de pessoas que chegam à Corte. Por determinação do Estatuto da própria Corte, ela só pode julgar casos envolvendo Estados-membros da OEA e a Comissão Interamericana de Direitos Humanos (PIOVESAN, 2015, p. 156), o

\footnotetext{
17 "De uma construção estabelecida Bourdieu não nega a mudança, mas chama a atenção em que períodos de transição, a resistência incorporada e silenciosa se opõe às estratégias de mudanças, estas definidas pelo mesmo passado que agora é combatido. [...] Nessas condições, o embate está nos agentes em dar formato em posições que ocupam, ou os postos a serem alcançados, mesmo que criando em certas situações algumas deformações, moldando esses agentes e/ou postos. Em momentos de crise, o discurso que surge cria novo senso comum coberto por uma legitimidade, a partir de uma autoridade que manifesta expressão de experiências no campo emergente, incutindo uma maneira de viver e entender o mundo social. Uma nova divisão vai criar resistências daqueles que estão perdendo posições como um anova representação mais elevada em nome de uma unidade, incorporando um discurso de bom senso, trabalhando com a neutralização da ordem social e um "discurso político despolitizado". (SANTOS, p.92)
} 
que significa que os casos que chegam à Corte já passaram inicialmente pela Comissão, órgão que recebe as denúncias individuais em casos de violação, e os processa, ouvindo o Estado-membro e colhendo provas. Em situações em que não tenha se chegado a uma solução amistosa, e a Comissão entenda pela existência de violação de direitos previstos na Convenção, determinará recomendações aos Estados que tem um prazo de três meses para adotar as providências designadas. Se não o fizer, a Comissão leva o caso à Corte (PIOVESAN, 2015, p. 148).

A lógica desse sistema, pautada na existência de um órgão jurisdicional ao qual conseguem chegar apenas a Comissão Interamericana e os Estados-membros da OEA não está livre de críticas. Trata-se de revestir a estrutura de proteção dos direitos de atores distantes da realidade social, com uma linguagem particular ${ }^{18}$, o que dificulta o acesso daqueles mais interessados na sua efetividade: os cidadãos. Como observa Paulo Weil (2010, p.91):

O entendimento dos direitos humanos não encontra na tecnologia jurídica seu meio de acesso por excelência. Ao contrário, somos levados a perceber que a literatura jurídica convencional, em certos casos, pautada por regras formais, consiste em óbices para o acesso a esses direitos. Esse processo abre espaço ao fortalecimento dos atores da sociedade civil, em um processo que os legitima como interlocutores e fortalece a própria sociedade civil como locus privilegiado da criação do direito. Esse processo implica uma crítica profunda à tradição do direito, que se afastou historicamente dos compromissos com os conteúdos valorativos estruturantes da sociedade política, em razão da afirmação da ciência, ao modelo da revolução científica, livre de todos os subjetivismos.

De fato, na medida em que o sistema interamericano de direitos humanos só pode ser buscado quando esgotados todos os meios jurídicos capazes de corrigir as violações de direitos no plano interno, é certo que são pouquíssimos os casos que encontram agentes da sociedade com fôlego para levar a reclamação para o foro supraestatal. Basta ver que até a presente data, apenas 9 casos contenciosos de violação de direitos humanos contra o Brasil chegaram à Corte: 1) Vladimir Herzog e outros Vs. Brasil (abril, 2016); 2) Povo Indígena Xucuru e seus membros Vs. Brasil (março 2016); 3) Cosme Rosa Genoveva, Evandro de Oliveira e outros (Favela Nova Brasília) Vs. Brasil (maio 2015); 4) Trabalhadores da Fazenda Brasil Verde Vs. Brasil (março 2015); 5) Julia Gomes Lund y otros ("Guerrilha do Araguaia") Vs. Brasil (março 2009); 6) Arley José Escher e outros Vs. Brasil (dezembro 2007); 7) Sétimo Garibaldi Vs. Brasil (dezembro 2007); 8) Gilson Nogueira de Carvalho e outro Vs. Brasil (janeiro 2005); 9) Damião Ximenes Lopes Vs. Brasil (outubro 2004) (OEA).

Todavia, o sistema tem providenciado importantes aberturas. A partir de 2001, o Regimento Interno da Corte admitiu a participação no processo das vítimas da violação de direitos humanos, ou seus familiares (nos casos em que a vítima não pode estar presente, como os casos de desaparecimento forçado, ou em casos de morte), ou ainda de Organizações Não-Governamentais que as representem (CANÇADO TRINDADE, 2003,

\footnotetext{
${ }^{18}$ Como observa Santos, "a produção dos discursos, com a finalidade de se tornarem legítimos, confere autoridade a quem os produz numa 'criação continuada', que reflete o choque de interesses envolvidos. Escritores, gramáticos, pedagogos e jornalistas exercem sobre a cultura um poder simbólico, estabelecendo uma linguagem selecionada e restrita, de pouco acesso ao uso popular" (p. 93)
} 
103). Esse fator mostra que o indivíduo não se vê como destinatário da violência simbólica a ser aplicada pela Corte, mas sim como um interessado em ver essa violência aplicada contra o Estado-membro.

Assim, no campo do sistema interamericano de direitos humanos, tem-se de um lado da Corte Interamericana os sete juízes responsáveis pela missão de dizer o direito, e do outro, a Comissão como órgão que procura responsabilizar o Estado pela violação de direitos, o Estado realizando a sua defesa, e as próprias vítimas, como agentes interessados em uma prestação jurisdicional que reconheça a idoneidade de sua pretensão, ou, em outras palavras, a responsabilidade do Estado pela violação de seus direitos. Trata-se de um processo de reconstituição da realidade dentro das regras do próprio campo (BOURDIEU, 2002, p. 229), em que a estrutura regional interamericana sai reforçada a cada causa julgada, na medida em que as partes buscaram nela a solução dos conflitos reconhecendo a evidente falibilidade do Estado moderno soberano na proteção da pessoa humana.

Se a posição dominante desse campo é a autoridade legítima para definir a interpretação e a aplicação dos direitos humanos, é certo que ele não é econômico, mas próprio do campo, correspondendo ao reconhecimento que os demais atores do campo fazem em relação aos juízes da Corte Interamericana. Aliás, como Bourdieu observou, o capital próprio de um campo não tem o mesmo valor em outros campos e só poderá eventualmente migrar de um campo para o outro com algum deságio, alguma taxa de conversão (BOURDIEU, 2003, p. 121). É precisamente nesse sentido que se verifica que o capital político amealhado por certos Estados, ou ainda o capital econômico, não tem o mesmo valor no campo do sistema regional de direitos humanos. Nesse campo, os Estados agem como justiciáveis e devem se submeter às decisões proferidas pela Corte, sendo que mesmo países dotados de reconhecido capital político (mesmo num suposto campo da política internacional) não logram transferir para o campo do sistema interamericano o mesmo capital, muitas vezes sofrendo condenações em sentenças judiciais.

Contudo, a questão que resta a enfrentar diz respeito a uma particularidade muito específica do campo do sistema interamericano de direitos humanos: a ausência de um órgão dotado de poder de polícia, ou seja, capaz de transformar a violência simbólica das decisões judiciais em autêntica força se necessário à determinação de condutas a serem adotadas pelos Estados demandados. Se no campo jurídico idealizado por Bourdieu existe o Estado, como órgão máximo da repressão, pode obrigar condutas através de seus organismos policiais, tal não ocorre no sistema internacional. De fato, é da própria lógica do sistema regional a ausência de um organismo com esse poder compulsório, pois sua configuração representaria paradoxalmente um enfraquecimento de direitos humanos e da independência necessária aos Estados para promove-los.

A OEA, bem como os órgãos que a compõem, atuam pelo poder de convencimento, pela racionalidade, e não pela força. Assim, na ausência de um elemento dentro do próprio campo que garanta compulsoriamente a eficácia de suas decisões, procura-se, na terceira parte desse trabalho procurar compreender o fenômeno sob as 
lentes de Pierre Bourdieu.

\section{DECISÕES JUDICIAIS DA CORTE INTERAMERICANA E A RESPONSABILIDADE DO CAMPO JURÍDICO INTERNO}

Uma decisão final da Corte Interamericana não estabelece penas pessoais (já que não corresponde a um tribunal penal), mas responsabiliza Estados e determina que sejam adotadas medidas capazes de reparar os danos causados pela violação de direitos humanos, bem como prevenir para que as violações em questão não voltem a acontecer. Trata-se de medida com "força jurídica vinculante e obrigatória, cabendo ao Estado seu imediato cumprimento" (PIOVESAN, 2015, p. 157). ${ }^{19}$

Pode determinar uma série de condutas, desde o pagamento de indenização às vítimas ou seus familiares, até providências que envolvam mudanças no direito interno, responsabilização, treinamento ou capacitação de agentes estatais. A título de ilustração ${ }^{20}$, no caso Gomes Lundt vs. Brasil, em que o Estado foi condenado em razão da violação de diversos direitos humanos dos integrantes da Guerrilha do Araguaia, de 1970 a 1974, bem como de suas famílias em sentença proferida em 2010, as obrigações a serem atendidas pelo Estado foram as seguintes:

a) Conduzir eficazmente, na jurisdição ordinária, a investigação penal dos fatos do presente caso a fim de esclarecimentos, determinar as correspondentes responsabilidades penais e aplicar efetivamente as sanções e consequências que a lei preveja; b) realizar todos os esforços possíveis para determinar o parâmetro das vítimas desaparecidas, cujos restos mortais, previamente identificados, deverão ser entregues a seus familiares com a maior brevidade e sem custo algum para eles; c) providenciar tratamento médico e psicológico que requeiram as vítimas; d) realizar as publicações determinadas na sentença; e) realizar um ato público de reconhecimento de responsabilidade internacional em relação aos fatos do presente caso; f) implementar um programa ou curso permanente e obrigatório de capacitação e formação em direitos humanos dirigidos aos membros das Forças Armadas; g) adotar as medidas que sejam necessárias para tipificar o delito de desparecimento forçado de pessoas em conformidade com os standarts interamericanos; h) continuar as iniciativas de busca, sistematização e publicação de toda informação sobre a Guerrilha do Araguaia, assim como da informação relativa às violações de direitos humanos ocorridas durante o regime militar, garantindo o acesso à mesma; e i) pagar as quantidades fixadas a título de indenização por danos materiais e imateriais, e reintegrar custas e gastos.

No tocante ao pagamento de indenizações, a própria Convenção Americana de Direitos Humanos determina que a sentença da Corte corresponde a um título judicial (art. 62.2, da CADH), o que implica a possibilidade de os valores nela estipulados serem cobrados diretamente pelas vítimas ou familiares através de órgãos jurisdicionais internos.

Mas o que ocorre quando um Estado condenado não cumpre as determinações na sentença? Theresa

\footnotetext{
${ }^{19}$ Em sentido contrário, adotando posição mais conservadora a respeito da eficácia das sentenças, Thereza Raquel Correia afirma que elas não têm força punitiva, mas procuram apenas assegurar "ações corretivas para as deficiências dos sistemas jurisdicionais nacionais" (CORREIA, 2008, p. 132).
} 
Raquel Couto Correia (2008, p. 133) lembra que caberá à Corte comunicar o fato à Assembleia Geral da OEA (art. 65, da $\mathrm{CADH}$ ), que poderá adotar sanções de caráter político e moral. Trata-se de uma estratégia conhecida como naming and shaming, em que o Estado que descumpriu a decisão é posto em evidência a fim de provocar as gestões diplomáticas para o adimplemento da decisão. Existe, teoricamente, porque até hoje não foi utilizado, a possibilidade de a Assembleia Geral emitir resolução (sem força vinculante) "recomendando aos demais Estadosparte da OEA que imponham sanções econômicas ao Estado violador até que a decisão do órgão do SIDH em questão seja implementada" (BERNARDES, 2011).

Como a Convenção Americana não estabelece um mecanismo específico de monitoramento para o cumprimento das decisões da Corte, essa situação tem comprometido a eficácia desses julgados, os quais são, via de regra, respeitados e cumpridos no tocante à condenação em valores pecuniários (até por força da própria disposição normativa da Convenção), mas não impulsionam os Estados a adotar as condutas previstas, como responsabilização de agentes responsáveis pelas violações de direitos humanos, revisão de legislação. Em situações como estas, Cançado Trindade (2003, p. 434) relata que a própria Corte tem dedicado seu tempo e seus esforços à supervisão da execução das sentenças.

Não há, dessa forma, nenhum órgão capaz de implementar, pelo uso da força, o cumprimento dessa sentença. No direito interno, a violência simbólica da sentença não afasta eventual necessidade de violência física segundo teorizou Bourdieu (TAVARES NETO, MEZZAROBA, 2016, p. 11), afinal é ela que, em última instância determinará o cumprimento das obrigações judicialmente estabelecidas. Não é esta a realidade, contudo, no direito interamericano dos direitos humanos, e nem poderia sê-lo, já que a lógica é a da democracia, da racionalidade, do argumento.

Como ressalta Piovesan, o sistema interamericano deixa poucas amarras para sanções no plano internacional. Não há "previsão de sanção ao Estado que, de forma reiterada e sistemática, descumprir as decisões internacionais", diferentemente do que ocorre no sistema europeu de proteção de direitos humanos, no qual um comportamento de reiterado descumprimento das decisões da Corte pode levar à expulsão do Estado da organização supra estatal (PIOVESAN, 2015, p. 176).

A relação entre os organismos internacionais e o Estado, via de regra, é de direção, e não de coação (BOBBIO, 2004, p. 37). Para que esses mecanismos de direção efetivamente funcionem, seria necessária a realização concomitante de duas condições: a) o órgão internacional deve ser dotado de elevada autoridade, gerando respeito por parte do Estado; e b) o Estado deve ser extremamente razoável em suas ações, demonstrando uma disposição genérica a cumprir as determinações desse órgão em consideração da sua racionalidade (BOBBIO, 2004, p. 37). No caso da Corte Interamericana, é preciso reconhecer que nem sempre

${ }^{20}$ Para uma análise mais completa dos julgados da corte, ver Piovesan, 2015, p.157-173. Todos eles implicam condutas materiais vol.10, nº. 03, Rio de Janeiro, 2017.pp. 1432-1452 
ela goza de elevada autoridade no sistema interno dos Estados, nem estão eles dispostos a cumprir de pronto todas as suas recomendações.

É o que se depreende de depoimentos dados por dois então ministros do Supremo Tribunal Federal brasileiro, precisamente a respeito das determinações da Corte no caso Gomes Lundt, mencionado supra:

O presidente do Supremo Tribunal Federal, Cezar Peluso, afirmou nesta quarta-feira (15/12) que a punição do Brasil na Corte Interamericana da Direitos Humanos (CIDH) "não revoga, não anula, não caça a decisão do Supremo" em sentido contrário. Em abril deste ano, o STF decidiu, por 7 votos a 2, declarar a constitucionalidade da Lei de Anistia ao decidir uma ação ajuizada pela Ordem dos Advogados do Brasil. (...)

O ministro negou a possibilidade de rever a decisão do Supremo e afirmou que o que pode ocorrer é o país ficar sujeito a sanções previstas na convenção ratificada pelo Brasil para integrar a Organização dos Estados Americanos (OEA). Peluso ainda afirmou que caso alguém entre com um processo contra eventuais responsáveis, a pessoa que se sentir prejudicada "vai entrar com Habeas corpus e o Supremo vai conceder na hora".

Para o ministro Marco Aurélio Mello, o Direito interno, pautado pela Constituição Federal, deve se sobrepor ao Direito internacional. "Nosso compromisso é observar a convenção, mas sem menosprezo à Carta da República, que é a Constituição Federal". Ele ainda afirmou que a decisão da CIDH tem eficácia apenas política e que "não tem concretude como título judicial. Na prática, o efeito será nenhum, é apenas uma sinalização" (CONJUR, 2010, grifo nosso).

Significa reconhecer que a decisão que é proferida com elevado capital jurídico no campo do sistema interamericano dos direitos humanos acaba por perder significação quando o Estado é chamado a cumprir suas determinações. Esta decisão acaba sendo transposta para o campo do direito interno sem a necessária autoridade, pois não pode utilizar os mecanismos coercitivos desse campo. E na ausência de outros (como uma sociedade civil organizada para monitorar o adimplemento das obrigações, um Judiciário deferente e afinado com as pautas de direitos humanos, agentes estatais capacitados para agir em respeito aos direitos humanos), perde em efetividade. ${ }^{21}$

Como já mencionava Bourdieu, o trânsito de agentes de um campo social para o outro sempre se dá com perdas significativas. A conversão do capital amealhado em um campo não resultará no mesmo capital em outro campo. Dessa forma, o capital jurídico de um juiz da Corte Interamericana não é significativo no campo jurídico interno, assim como o capital político de um Estado não modifica sua responsabilidade no campo do sistema interamericano (MONTAGNER, 2010, p. 263).

Diante dessa difícil realidade, Flávia Piovesan (2015, p. 175) propõe que se incremente os mecanismos de cumprimento das sentenças internacionais no âmbito doméstico, de modo que os Estados adotassem

aos Estados.

${ }^{21}$ É o que salienta Márcia Nina Bernardes: "No que se refere aos atores jurídicos brasileiros, o desconhecimento acerca das nossas obrigações internacionais discutido acima é responsável pela maior parte das condenações contra o Brasil e das dificuldades em cumprir as determinações dos órgãos do sistema interamericano. Isso se deve ao fato de que a principal causa das declarações de responsabilidade internacional do Brasil é a violação ao artigo 1.1 (dever geral de garantia) combinado com os artigos $8^{\circ}$ (garantias processuais) e 25 (proteção judicial) da CADH. Esse quadro poderia ser revertido, ou amenizado, se nossos atores jurídicos se utilizassem rotineiramente dos padrões internacionais de proteção aos direitos humanos" (2011). 
legislação interna tratando da implementação das decisões internacionais sobre direitos humanos. Nesse sentido, propõe:

As decisões internacionais em matéria de direitos humanos devem produzir efeitos jurídicos imediatos e obrigatórios no âmbito do ordenamento jurídico interno, cabendo aos Estados sua fiel execução e cumprimento, em conformidade com o princípio da boa-fé, que orienta a ordem internacional. A efetividade da proteção internacional dos direitos humanos está absolutamente condicionada ao aperfeiçoamento das medidas nacionais de implementação.

Nessa toada, a proposta parece significar a incorporação, pelo campo jurídico, de elementos próprios do campo do sistema interamericano, a fim de garantir-lhe maior eficácia. A decisão assim, absorvida pelo direito interno, passaria a gozar da autoridade própria das sentenças judiciais proferidas pelos juízes dos Estados, dotadas de universalidade porque aplicáveis a todos as pessoas (inclusive ao Estado) e por elas reconhecida. Dessa forma, os "poderes socialmente reconhecidos consagram a ordem sob a tutela do Estado, produzindo uma eficácia do direito" sem margem para dúvidas, pois não se funda exclusivamente na coerção, mas corresponde às expectativas e necessidades reais da sociedade (SANTOS, p. 98).

Embora se reconheça que a existência de um sistema de proteção de direitos humanos de fato atende às expectativas das sociedades latino-americanas, é preciso ter em mente que as decisões da Corte, quando são vistas por estes Estados e estas sociedades, estão travestidas da imagem do estrangeiro, do estranho ao campo jurídico doméstico e, portanto, da efetividade que a este último é atribuída. Se, como propõe Piovesan, elas ingressarem o campo jurídico interno como se decisões internas fossem, a partir de uma legitimação determinada pelo próprio ordenamento, poderiam gozar do mesmo alcance e efetividade.

\section{CONSIDERAÇÕES FINAIS}

As contribuições de Pierre Bourdieu permitiram verificar a identificação de um outro campo social, paralelo ao campo jurídico inerente aos Estados, qual seja, o campo do sistema interamericano dos direitos humanos. Trata-se de um espaço de lutas pela dominação de determinar o sentido dos direitos humanos, com estrutura própria e atores dotados de capital jurídico próprio.

No campo jurídico teorizado por Bourdieu, aqueles que dominam a linguagem jurídica e manifestam-se de acordo com o habitus próprio do campo acabam por contribuir para a definição da interpretação e aplicação das normas jurídicas, solucionando os casos que deixam o campo das realidades sociais para passar por um processo de ressignificação, em que são revestidos de linguagem jurídica e resolvidos a partir das categorias jurídicas. O justiciável é aquele que precisamente pretende ingressar no campo, abrindo mão da solução de seus conflitos por seus próprios meios e aceitando as determinações dos juízes, aceitando a qualificação dos fatos feita pelos advogados. Ele não domina a linguagem jurídica, não domina os rituais, é o profano que se vê dominado em um campo buscado espontaneamente. E aceita a dominação que lhe é imposta como legítima, reconhece sua 
validade, e pauta sua existência a partir do que for determinado pelos dominantes do campo, pois essa é a medida da justiça.

No campo do sistema interamericano também se realiza esse processo de dominação, na qual especialmente os juízes da Corte, dotados de elevado capital jurídico tanto na atividade prática de aplicação das normas jurídicas, quanto na teorização sobre o seu sentido, já que egressos da academia, definem a interpretação dos direitos humanos tendo por norte a promoção e proteção do valor ético de cada indivíduo. Nesse caso, os Estados-membros da OEA ingressam no campo como justiciáveis, mas não o procuraram, são a ele chamados pela Comissão e pela Corte, em virtude de denúncias feitas pelas vítimas de violação de direitos humanos. Embora os Estados tenham reconhecido a competência da Corte, o fazem de forma simbólica, para adequarem-se a um padrão internacional que não mais tolera o desrespeito aos direitos humanos. Quando são demandados, e deles exigidas condutas específicas para realização desses direitos, assumem posição reticente, e voltam a invocar a soberania nacional como escudo para suas ações.

Assim, os Estados aceitam a imposição de sentenças determinando a salvaguarda de direitos humanos, bem como da violência simbólica que elas materializam. Mas o fazem de forma insincera, já que no campo jurídico interno poucas são as ações que adotam para efetivamente cumprir essas decisões judiciais. No campo do direito interno, as decisões internacionais perdem força, os atores então dominantes no plano internacional, não têm capital suficiente para se impor nesse campo.

Diante dessa realidade, a proposta de criação de legislação interna regulando o cumprimento dessas decisões alienígenas no campo jurídico doméstico pode representar uma alternativa a esse processo de negligência e descaso. Se no campo interno o Judiciário é dotado de mecanismos coercitivos capazes de conduzir o cumprimento de suas decisões, é precisamente nesse campo que devem se erguer estruturas capazes de proteger os direitos humanos.

\section{PIERRE BOURDIEU'S CONTRIBUITION TO UNDERSTAND THE APPLIANCE OF THE INTERAMERICAN COURT OF HUMAN RIGHTS'S ADJUDICATIONS}

\footnotetext{
Abstract

The OAS system of human rights responded to an insufficient promotion and protection of Latin-American States' citizens human rights by their internal laws. However, the OAS Human Rights Court's adjudications face severe resistance from the Member-States in their implementation, specially when prescribing the criminal and civil liability of the agents held responsible for human rights violations. This article intended, from Pierre Bourdieu's categories like field of law and symbolic violence, to demonstrate the conformation of a social field that corresponds to the acting of this international system's organisms, aiming to investigate the low effectiveness of its rulings.
} 
Keywords: Human Rights Inter-american Court. Adjudication. Field. Symbolic Violence.

\section{REFERENCIAS BIBLIOGRÁFICAS}

ARENDT, Hannah. As origens do totalitarismo. Trad. Roberto Raposo. São Paulo: 2012.

BARROS FILHO, Clóvis. Os campos sociais (aula). São Paulo: Universidade de São Paulo. Disponível em: <https://www.youtube.com/watch?v=B8bXT3iCW8w>. Acesso em: 24 jun. 2016.

BECATTINI, Natália. Veja quais países da América Latina tiveram ditaduras militares. In: Guia do Estudante, 20/11/2013. Disponível em: <http://guiadoestudante.abril.com.br/fotos/paises-america-latina-tiveramditaduras-militares-760783.shtml\#13>. Acesso em: 20 ago. 2016.

BERNARDES, Márcia Nino. Sistema Interamericano de Direitos Humanos como esfera pública transnacional: Aspectos jurídicos e políticos da implementação de decisões internacionais. In: Conectas Direitos Humanos. Edição V. 8, n. 15, Jan. 2011. Disponível em: <http://www.conectas.org/pt/acoes/sur/edicao/15/1000175sistema-interamericano-de-direitos-humanos-como-esfera-publica-transnacional-aspectos-juridicos-e-politicosda-implementacao-de-decisoes-internacionais>. Acesso em: 10 ago. 2016.

BOBBIO, Norberto. O Terceiro Ausente: ensaios e discursos sobre a paz e a guerra. Barueri: Manole, 2009. A era dos direitos. Trad. Carlos Nelson Coutinho. Rio de Janeiro: Elsevier, 2004.

BOURDIEU, Pierre. O poder simbólico. Trad. Fernando Tomaz. 5a ed. Rio de Janeiro: Bertrand Brasil, 2002. Questões de sociologia. Trad. Miguel Serrás Pereira. Lisboa: Fim de Século, 2003.

BRASIL. Ato Institucional n. 5, de 13 de dezembro de 1968. São mantidas a Constituição de 24 de janeiro de 1967 e as Constituições Estaduais; O Presidente da República poderá decretar a intervenção nos estados e municípios, sem as limitações previstas na Constituição, suspender os direitos políticos de quaisquer cidadãos pelo prazo de 10 anos e cassar mandatos eletivos federais, estaduais e municipais, e dá outras providências. Disponível em: <http://www.planalto.gov.br/ccivil_03/AIT/ait-05-68.htm>. Acesso em: 10 ago. 2016.

CANÇADO TRINDADE, Antônio Augusto; ROBLES, Manuel E. Ventura. El Futuro de la Corte Interamericana de Derechos Humanos. Costa Rica: Corte Interamericana de Direitos Humanos, 2003.

COMPARATO, Fábio Konder. A afirmação histórica dos direitos humanos. 10 ed. São Paulo: Saraiva, 2015.

CONJUR. Condenação do Brasil não anula decisão do Supremo. In: Revista Consultor Jurídico. 15 dez. 2010. Disponível em: <http://www.conjur.com.br/2010-dez-15/sentenca-corte-interamericana-nao-anula-decisaosupremo $>$. Acesso em: 20 ago. 2016.

CORREIA, Theresa Raquel Couto. Corte Interamericana de Direitos Humanos: Repercussão Jurídica das Opiniões Consultivas. Curitiba: Juruá, 2008.

CORTE INTERAMERICANA DE DIREITOS HUMANOS. Court Hirstory. Disponível em: <http:/ / www.corteidh.or.cr/index.php/en/about-us/historia-de-la-corteidh>. Acesso em 18 ago 2016. 
CORTE INTERAMERICANA DE DERECHOS HUMANOS. Composición Actual. San Jose, 2016. Disponível em: <www.corteidh.or.cr/index.php/es/acerca-de/composicion>. Acesso em 10 ago. 2016

DUARTE JUNIOR, Dimas Pereira. Accountability e Relações Internacionais. Ponto-e-Vírgula. Revista de Ciências Sociais. N. 4, segundo semestre 2008. Disponível em: <http://revistas.pucsp.br/index.php/pontoevirgula/article/viewFile/14152/10400>. Acesso em: 04 ago. 2016.

MONTAGNER, Miguel Ângelo; MONTAGNER, Maria Inez. A teoria geral dos campos de Pierre Bourdieu: uma leitura. In: Revista Tempus Actas de Saúde Coletiva: nov. 2010, p. 255-273.

NIETO NAVIA, Rafael. La jurisprudencia de la corte interamericana de derechos humanos. In: CORTE INTERAMERICANA DE DERECHOS HUMANOS. Estudios y Documentos. San Jose: IIDH, 1988.

OEA. Comissão Interamericana de Direitos Humanos (CIDH). Decisões. Casos na Corte. Disponível em: $<$ oas.org/pt/cidh/decisiones/demandas.asp >. Acesso em: 20 ago. 2016.

PETERS, Gabriel. Habitus, reflexividade e neo-objetivismo na teoria da prática de Pierre Bourdieu. In: Revista Brasileira de Ciências Sociais. V. 28 n. 83, outubro/2013. Disponível em: < http://www.scielo.br/scielo.php?script=sci_arttext\&pid=S0102-69092013000300004>. Acesso em: 20 jun. 2016.

PIOVESAN, Flávia. Direitos Humanos e a Justiça Internacional. São Paulo: Saraiva, 2015.

SANTOS, Márcio Achtschin. Uma leitura do campo jurídico em Bourdieu. Águia: Revista Científica da Fenord, vol. $\quad 1$ ano $1, \quad$ p. 86-101. Disponível em < http://www.fenord.com.br/revistafenord/revista_topicos/Umaleituradocampojuridicopag86.pd f $>$. Acesso em: 10 ago. 2016.

TAVARES NETO, José Querino; MEZZAROBA, Orides. O método enquanto pressuposto de pesquisa para o Direito: a contribuição de Pierre Bourdieu. In: Revista da Presidência da República. Brasília, 2016.

WEIL, Paulo. América Latina: entre a afirmação e a permanência da violação de direitos humanos. In Hendu, Revista Latino-Americana de Direitos Humanos. n. 1, julho 2010. Disponível em: <http://periodicos.ufpa.br/index.php/hendu/article/view/372/598>. Acesso em: 20 ago. 2016.

Trabalho enviado em 09 de setembro de 2016.

Aceito em 04 de março de 2017. 